\title{
Aspectos da escolarização de mulheres na EJA
}

\author{
Carmem Lucia Eiterer* \\ Jacqueline D'arc Dias** \\ Marina Coura***
}

\section{Resumo}

Fundamentando-se na pesquisa de natureza qualitativa, realizada por meio de entrevistas com 14 mulheres, mães de crianças pequenas matriculadas na Educação de Jovens e Adultos no nível fundamental, em instituiçóes de ensino tradicionais e reconhecidas (uma pública e uma privada) de Belo Horizonte, neste artigo serão discutidos aspectos relativos à escolarização e seus efeitos no âmbito familiar a luz de contribuiçôes teóricas do campo de estudos de gênero. Considerando a divisão por gênero das responsabilidades do trabalho doméstico na sociedade brasileira, debate-se a sobrecarga de atividades que se impóe à mulher mãe trabalhadora. Para tal, examinase a sua condição de escolarização, bem como a relação com a escolarização dos filhos e a cultura escrita familiar. Evidencia-se como resultado o esforço de negociação que empreendem a fim de garantir sua possibilidade de se matricular na escola e as dificuldades que enfrentam para acompanhar a escolarização dos filhos na sua tríplice condição de mãe, trabalhadora e estudante.

Palavras-chave: Gênero. Educação de adultos. Letramento.

\footnotetext{
* Doutora em Educação pela Universidade de São Paulo (USP). Professora da Faculdade de Educação e do Programa de Pós-Graduação em Educação da Universidade Federal de Minas Gerais (UFMG).

** Graduanda em Matemática pela Universidade Federal de Minas Gerais (UFMG). Bolsista PROBIC/FAPEMIG.

${ }^{* * *}$ Graduanda em Dança pela Universidade Federal de Minas Gerais (UFMG). Bolsista PROBIC/ FAPEMIG.
} 


\section{Introdução}

Este artigo $^{1}$ é fruto de uma pesquisa acerca do processo de escolarização de mulheres na modalidade Educação de Jovens e Adultos (EJA), na qual examinamos se havia e quais seriam os efeitos do ato de frequentar a escola para essas mulheres - mães ou responsáveis por crianças com idade entre 6 e 14 anos - sobre suas vidas e as de suas famílias, do ponto de vista da cultura escrita familiar. Visávamos entender como seu retorno à escola afetaria a escolarização dos filhos, focalizando as açôes familiares em torno da aquisição da leitura e escrita, da realização de tarefas escolares e da ampliaçáo dos níveis e práticas de letramento de ambos os sujeitos - máes e filhos. Considerava-se, como hipótese inicial, a possibilidade de transmissão de valores escolares entre as geraçốes.

Aprofundando o estudo sobre esse tema, neste artigo, objetivamos compreender alguns fenômenos relativos à educação de pessoas jovens e adultas cujas trajetórias escolares se deram na modalidade EJA. Portanto, nesta investigação, procura-se compreender as motivaçôes que trazem o adulto (a mulher, mãe, trabalhadora) de volta à escola, as razōes que os mantém frequentes noite após noite, ano após ano e, especialmente, em que condiçôes esse retorno ocorre. Rosemberg, Pinto e Negrão (1982) já destacaram ser fato relevante o aumento do grau da escolarizaçáo da mulher no Brasil. Entretanto, segundo as autoras, pouco ou quase nada se sabia sobre os efeitos dessa escolarização, nem da utilização que as mulheres faziam dela em suas vidas.

Contudo, segundo os dados da Pesquisa Nacional por Amostra de Domicílios do Instituto Brasileiro de Geografia e Estatística (Pnad/IBGE) de 2009, divulgados em 2010, já houve aumento na diferença de anos de estudo entre homens e mulheres. A média de anos de estudo das mulheres é maior em todas as faixas etárias, com exceção dos mais velhos (60 anos ou mais), dedicando-se 7,4 anos aos estudos, contra 7 anos dos homens. Na faixa dos 20 aos 29 anos, a diferença é ainda mais evidente: enquanto as mulheres acumulam 10 anos estudando, os homens somam 9. A nosso ver, a constatação de que pouco se sabe a respeito do uso da escolarização no cotidiano dessas mulheres continua válida nos dias atuais e constitui a principal fundamentação de nossa proposta de investigação.

Nesta perspectiva, propóe-se desenvolver uma investigação de natureza qualitativa por entender, assim como Minayo (1993), que essa modalidade de pesquisa responde questóes muito particulares, permitindo-nos aproximar 
do universo de valores e atitudes dos sujeitos, o que nos escaparia realizando outras modalidades de pesquisa. Portanto, a escolha da entrevista, instrumento usual neste tipo de pesquisa, ocorreu por se tratar de uma técnica que permite ao informante abordar livremente o tema proposto. Consideramos que as informantes selecionadas para o estudo possuíam um conhecimento elaborado sobre o tema em questão. Enfim, outra forma de coleta de dados não abarcaria adequadamente a complexidade do tema a ser exposto.

\section{O perfil dos sujeitos da pesquisa}

Para selecionar os sujeitos da pesquisa, entramos em contato com duas escolas que trabalham com a modalidade EJA no período noturno em Belo Horizonte: uma pública, localizada na zona Oeste da Capital e uma privada, de natureza filantrópica, na zona Sul. Identificamos, então, 22 mulheres que atendiam ao corte que delimitamos anteriormente ${ }^{2}$. Destas, 14 foram entrevistadas. Vale ressaltar que a indisponibilidade de tempo para os encontros (apesar da manifestação de seu desejo de contribuir) prejudicou a realização de mais entrevistas, aliás, uma característica desse grupo, como discutiremos no decorrer deste trabalho. Apresentamos, sinteticamente a seguir, um breve perfil das entrevistadas, cujas identidades estáo protegidas sob o uso de nomes fictícios.

\section{Grupo 1 - Matriculadas na $1^{\underline{a}}$ etapa do Ensino Fundamental:}

a) Helena, 65 anos. Parda de ascendência indígena. Matriculada na $2^{\text {a }}$ série do Ensino Fundamental. Voltou a estudar após ficar viúva. Cuida sozinha de todos os serviços da casa e dos netos em idade escolar. Trabalhou com carteira assinada em serviços de limpeza e conservaçáo em bancos e como doméstica em residências. Aposentada por problemas de saúde desde os 42 anos de idade, garante a manutenção da casa e da família com seu salário de aposentadoria e a pensão de viúva.

b) Luisa, 53 anos. Branca. Matriculada na 1a série do Ensino Fundamental. Filha de pais separados, que totalizam mais de 20 filhos. Empregada registrada em carteira de trabalho. Com 10 anos lavava roupa para fora, na casa da sogra do irmão que a acolheu. O irmão a matriculou na escola, mas ela não frequentou. Não contava com um adulto que supervisionasse sua frequência na escola. Com 15 anos veio para Belo 
Horizonte ser empregada doméstica em residência familiar. Mãe de 3 filhas. Hoje, após a gravidez precoce da filha do meio, que segundo ela se envolveu com um traficante de drogas, cria a neta por quem revelou, em seu depoimento, grande afeto.

c) Antonia, 46 anos. Negra. Matriculada na $3^{a}$ série do Ensino Fundamental. Solteira e mãe de 1 filha adolescente. Empregada de serviços gerais (limpeza, cozinha, passadeira). Trabalhadora formalmente registrada em carteira de trabalho. Não tem contato com o pai da filha. Tem 7 irmãos. Os pais faleceram e ela foi morar na casa da madrinha onde trabalhava e era impedida de frequentar a escola. Aprendera a ler e escrever com a filha de uma patroa com quem brincava de escolinha. Tem vínculo com uma irmá que a incentivou a voltar aos estudos e que sempre a apoiou.

d) Mirtes, 43 anos. Parda. Matriculada na 2a série. É irmã de Dulce. Doméstica, tem registro em carteira de trabalho. Recebe bolsaescola. Mãe de uma filha casada de 25 anos. Segundo ela, nenhum de seus irmãos estudou quando criança. A escola era muito longe e a jornada até ela tomava metade do dia, logo o pai julgava não valer a pena estudar e não incentivava. Trabalhou desde os 8 anos fazendo o almoço para levar ao pai e aos demais trabalhadores agrícolas que trabalhavam com ele. Hoje, como afirma, o namorado incentiva sua frequência à escola e a leva todos os dias. Está fazendo o curso para tirar sua carteira de motorista.

e) Dulce, 39. Parda. Matriculada na 2a série do Ensino Fundamental. Mãe de 7 filhos de quatro relacionamentos distintos. Não recebe nenhum tipo de auxílio dos pais de seus filhos. Nunca teve registro em sua carteira de trabalho embora tenha trabalhado na agricultura até adulta e, posteriormente, como doméstica. Desempregada. Recebe bolsa-escola. Em Belo Horizonte, há menos de 1 ano, reside na casa da irmã que a acolheu com os 4 filhos mais novos. Faz o trabalho doméstico na casa, pois a irmã trabalha fora. Foi criada pela avó depois que os pais se separaram, quando tinha 7 anos de idade. Parou de frequentar a escola quando o irmão que a acompanhava adoeceu e veio a falecer. A avó não permitiu que ela continuasse seus estudos sozinha. Mesmo quando ainda vivia com o pai, este não incentiva a escolarização. 
f) Dalva, 34 anos. Parda. Matriculada na $3^{a}$ série do Ensino Fundamental. Mãe de 2 filhos. Vítima de violência sexual por parte do padrasto, teve uma filha aos 13 anos. Não chegou a frequentar a escola. Sentia-se estigmatizada pela maternidade precoce. Morou parte do tempo com a avó, mas residiu, a maior parte de sua vida, sem a filha que deixou com a mãe, na casa de outras famílias onde trabalhava como empregada doméstica. Desligou-se dos irmãos e da família. Náo aceitava a filha e rompeu com a mãe que, segundo ela, não a vê como a vítima, permanecendo a viver junto ao abusador até a presente data: 20 anos após o ocorrido. Afirma que aprendeu a ler e escrever, ver as horas, com a filha de uma patroa. Destaca-se por se expressar em uma variante linguística muito diferenciada das demais entrevistadas. Segundo ela, aprendeu a falar direito, porque trabalhou em casa de gente rica. Seu filho mais jovem mantém contato com o pai embora não receba auxílio financeiro por parte dele. Trabalhadora formalmente registrada em carteira de trabalho.

g) Francisca, 33 anos. Parda. Matriculada na $3^{a}$ série do Ensino Fundamental. Casada, mãe de um menino de 7 anos, trabalha como babá. Trabalhadora formalmente registrada em carteira de trabalho. Segundo ela, não teve infância, foi separada dos irmãos, pois os tios pegaram as crianças para usar. Assim, desde os 9 anos, teve que se virar sozinha. Lavava, passava etc., dia e noite, em casa de parentes em troca de sobrevivência, logo, não tinha tempo pra estudar, não tinha tempo pra brincar, não tinha tempo pra nada. Considera a criança da casa onde trabalha, por quem demonstra afeto e cuidado, hoje, a sua companhia para brincar.

h) Laura, 25 anos. Parda. Trabalhadora formalmente registrada em carteira de trabalho como faxineira. Recebe bolsa-família. Matriculada na $1^{\text {a }}$ série do Ensino Fundamental. Mãe de um menino de 7 anos. Engravidou aos 17 anos e foi morar com o companheiro, pai da criança. Reside com a família em casa própria. $\mathrm{O}$ marido não permitia que frequentasse a escola, principiou por comparecer com ela, tendo conhecido o ambiente, aprovou e passou a permitir que frequentasse a escola sozinha. A mãe deixou a família na infância. Foi criada com apenas uma das irmâs. Conforme ela, o pai mudava frequentemente de residência, dado o valor do aluguel, obrigando-a a mudar de escola. 


\section{Grupo 2 - Matriculadas na 2a etapa do Ensino Fundamental:}

a) Gilda, 55 anos. Vive em união estável há 30 anos, com o marido e os dois filhos dele. Mãe de três filhos adultos. Trabalha como empregada doméstica há 16 anos na mesma residência, e possui registro formal em carteira de trabalho. Afirma ter sido leitora voraz de uma pluralidade autores e títulos, indo de Sidney Sheldon a Gabriel Garcia Márquez. Destaca que desde criança amava ler e sonha prosseguir na Faculdade e cursar Letras. Foi impedida de continuar na escola pela mãe (evangélica) que a obrigou a se casar ainda muito jovem com um pastor, o pai do filho mais velho, que conta 32 anos. Sua inclusão no corpus da pesquisa deveu ao fato de que até a ocasião da entrevista, sua neta de 7 anos (juntamente com a mãe e o pai) residiam com ela ${ }^{3}$.

b) Ana Maria, 46 anos. Solteira. Responsável por um adolescente de 12 anos - filho de uma sobrinha. Cabeleireira. Divide a casa com uma irmã. Apenas uma irmá, entre as sete, completou o Ensino Médio. Parou de estudar por ter que trabalhar para ajudar a mãe que passava por dificuldades. Retornou aos estudos para não ficar pra trás e mostrar pra si mesma que era capaz.

c) Joana, 38 anos, copeira. Casada, mãe de cinco filhos, entre 22 e 9 anos. Frequentou a escola por incentivo de uma avó. Após a morte da avó, aos 14 anos, teve seu primeiro filho e foi morar com o namorado para sair da responsabilidade da máe. Interrompeu os estudos e começou a ter trabalhos eventuais como faxineira. Engravidou do segundo filho de outro relacionamento e separou ainda grávida. Após o nascimento do segundo filho, conheceu seu atual marido com quem teve outros três filhos. Retornou aos estudos em 2013 pretendendo ser uma pessoa com mais conhecimento e ter outras possibilidades de emprego.

d) Léia, 38 anos, babá. Casada, mãe de dois filhos com idades de $13 \mathrm{e}$ 4 anos. Interrompeu os estudos na $5^{a}$ série, segundo ela, por querer aproveitar mais a vida. Aos 18 anos, mudou-se para Belo Horizonte para trabalhar como babá em busca de melhor salário e autonomia. Sente-se realizada com seu trabalho e atribui a ele as possibilidades que teve de viajar e de aproveitar a vida. Retornou aos estudos por 
sugestão da atual patroa. Quer se formar porque considera bom ter um diploma e náo por almejar outras possibilidades de emprego.

e) Rosangêla, 33 anos. Não teve oportunidade de frequentar a escola devido às várias mudanças de cidade, ocasionadas pelo pai religioso. Por ser a filha mais velha, depois da morte da mãe cuidou sozinha dos irmãos e de seu filho recém-nascido. Casou-se, teve mais um filho. Trabalha como manicure em um salão. Acolheu seu irmão caçula para morar junto à sua família. Fez inúmeras tentativas em vão para voltar a estudar, pois sua mãe havia perdido o histórico escolar. Voltou a estudar depois de ter sido convidada por uma cliente.

f) Sônia, 29 anos. Não trabalha fora, casada e mães de um filho de 8 anos. Teve trabalhos temporários como balconista e vendedora. Interrompeu os estudos após várias mudanças de cidade ocasionadas pelo pai religioso. Voltou a estudar por incentivo da irmã mais velha.

Como vimos na descrição dos perfis dessa população, a inserçẫo no campo da Educação de Jovens e Adultos, na idade adulta, significa conciliar diferentes responsabilidades com as tarefas, horários e outras exigências escolares. Para as mulheres, especialmente, o horário de trabalho, torna-se ainda maior, tendo que conciliar escola e responsabilidade por tarefas de cuidar da casa e da família (filhos, marido, eventualmente pais, netos e mesmo outros parentes).

\section{Um recorte nos Estudos de Gênero}

Dentre as muitas possibilidades teóricas no campo dos estudos de gênero, apoiamo-nos em algumas autoras que nos auxiliam pensar o trabalho feminino como fenômeno social e histórico. O trabalho feminino numa sociedade é caracterizado não como decorrência de qualquer tipo de dado natural ou biológico, pré-determinado e imutável. Não entenderemos aqui por feminino alguma essência fixa, mas algo que se apresenta a partir de relaçôes de gênero historicamente construídas ${ }^{4}$.

Nesse sentido, assinala Bila Sorj (2010, p. 57) que "as desigualdades e diferenças de gênero repousam sobre uma norma que associa o feminino à domesticidade e que se expressa na divisão sexual do trabalho, atribuindo prioritariamente às mulheres a responsabilidade com os cuidados da família". Logo, para as mulheres entrevistadas, em específico, retornarem à escola 
implicou coordenar responsabilidades de mãe, esposa, filha, dona de casa, estudante, trabalhadora, entre outros.

Todavia, discutir a natureza sócio-histórica da divisão por gênero do trabalho doméstico na sociedade brasileira nos leva a ver sobre vários ângulos. Sua natureza e duração são alguns deles. Um bom exemplo nos forneceu Laura ao referir à participação do marido no cuidado da casa: "Olha, tem vez que o L. me ajuda, mas tem vez que não. Agora mesmo, só quando ele quer. Homem é assim né, só faz quando quer" (Laura, 25 anos).

A propósito, a autora Maria Betânia Ávila (2013) tem se dedicado a analisar a importância e a natureza do trabalho feminino na nossa sociedade, destacando alguns aspectos que merecem ressalva. Segundo a pesquisadora, é

[...] muito difícil [...], trabalhar com a ideia de desigualdade, com dimensões que fazem as relações sociais, como contradição, exploração e dominação. Eu tento trabalhar nesta perspectiva, na construção da questão do trabalho doméstico, seja remunerada ou não, como uma relação de trabalho, como uma relação de contradiçãa, como uma relação de poder, como relação dominaçấo e exploração. (ÁVILA, 2013, p. 230).

Efetivamente, o trabalho feminino se caracteriza, em grande parte, como de cuidado e dentro dessa categoria encontra-se o trabalho doméstico. Na sua dupla natureza, como trabalho remunerado e não remunerado, o trabalho doméstico é, em grande parte, trabalho de natureza reprodutiva. Diferentemente do trabalho produtivo, considerado sincrônico, cuja natureza é definida por ter claramente demarcado um início e um fim, o trabalho reprodutivo é diacrônico, ininterrupto, invisível. Ele transborda fronteiras, frequentemente a mulher-mãe concilia a tarefa de cuidado da prole, monitorando a rotina da casa desde seu trabalho remunerado.

Assim, com o foco na diversidade das atividades desempenhadas, a pesquisa de campo mostrou que, embora a infância pobre atinja, igualmente, meninos e meninas, para as mulheres a divisão sexual de tarefas domésticas significou acúmulo de desvantagens sociais. Parece-nos bastante razoável apontar que, para elas, mulher e pobreza são categorias que configuram situaçốes de subordinaçáo de gênero e de classe.

Concordando com o que salientam Melo, Considera e Di Sabbato (2007, 
p. 437), evidencia-se que essas mulheres enfrentam o fenômeno da estabilização do masculino:

Para o caso brasileiro, isto é agravado pelas enormes desigualdades existentes entre as classes sociais, que permitiram que essa incorporação maciça de mulheres no mercado de trabalho tenha sido efetuada sem maiores mudanças nas relaçóes de gênero. As empregadas domésticas são um exército de mulheres pobres, com baixa qualificação, custo baixíssimo e representam o maior contingente de trabalhadoras do país.

Na mesma direção, segundo Kergoat (2001 apud AVILA, 2010), houve mudanças ao longo dos anos na sociedade ${ }^{5}$, mas no fundo o panorama permanece inalterado:

A divisão sexual do trabalho tem por características a designação prioritária dos homens à esfera produtiva e das mulheres à esfera reprodutiva, como também, simultaneamente, a captação pelos homens das funçóes com forte valor social agregado (políticos, religiosos, militares etc.). Esta forma de divisão social tem dois princípios organizadores: o princípio da separação (há trabalhos de homem e trabalhos de mulher) e o princípio hierárquico (um trabalho de homem 'vale' mais que um trabalho de mulher). (KERGOAT; 2001, p. 89 apud ÁVILA, 2010, p. 116).

Podemos questionar a ideia de hierarquização, recordando que não há, em essência, trabalho que seja em si mesmo feminino ou masculino. As atribuiçóes sociais estabeleceram esses lugares e podem ser alteradas. Os discursos das mulheres acerca do cotidiano revelam que tal exercício de negociaçáo em torno das diferentes responsabilidades não se dá sem conflito, porém a negociação e as atribuiçóes do trabalho doméstico vão se redefinindo. Como mostram os trechos apresentados a seguir, por vezes elas próprias consideraram inconciliáveis tais atividades:

$E$ ai eu arrumei esse outro menino e tal, e aquilo, eu fui agarrando ali, cuidando de menino, de casa e tudo e aí eu nem lembrei mais que existia estudo. (Rosângela, 33 anos). 
Às vezes me dava vontade de voltar a estudar, mas ia embora rápido. Porque a situaçáo só me levava a pensar em quê? Trabalhar, trabalhar, pra pelo menos ajudar a manter. (Joana, 38 anos).

Assim, se em algum momento, o retorno aos estudos não era cogitado por elas, ao decidirem retornar a ele, o conflito que antes se colocava apenas na dimensão interna (subjetiva) passa a se manifestar explicitamente na esfera doméstica de modo objetivo. A disputa cotidiana de poder se instala, tencionando as vidas familiares. Fazer valer o direito à escolarização leva a desmistificação do jargão "não tem necessidade". Isso está presente, a nosso ver, nas seguintes narrativas:

Ah, o marido não achou muita graça não, sabe? Não sei porque, mas, não gostou muito não, mas eu falei: "ah não", me proibir de estudar? Trabalhar, ninguém proibe, né? Por que é uma coisa pro meu bem, né? Não é uma coisa assim... Que não tem necessidade! Tem necessidade! Não achou muito bom não... (Rosângela, 33 anos).

Meu marido não gostou nem um pouco, ele não criticava não, mas ele não gostou. Não gostou porque ficou falando quem que ia ficar com os meninos, que os meninos ficavam o dia inteiro sem eu, porque eu ficava o dia todo fora e os meninos o dia todo fora, e que só via eles de manhã porque às vezes de noite eles já estavam dormindo. (Léia, 38 anos).

Quando eu falei assim: ô vou estudar. O marido nossa, ficou nervoso e me xingou. Porque eles pensaram no seguinte, pensaram na janta e na casa arrumada. Eles [filhos] não gostaram que eu voltei pra escola não, [...] e eu falei vocês gostando ou não eu vou continuar estudando. (Joana, 38 anos).

Nos depoimentos das mulheres ${ }^{6}$, a gestação, os cuidados com os filhos e a família constam frequentemente entre as principais razões apresentadas para o afastamento precoce da escola. Não podemos, contudo, desconsiderar o poder que exerceu a submissão ao pai ou ao marido entre estas razóes. Sorj (2010) recorda-nos que por muito tempo o trabalho de cuidados foi concebido como uma atividade naturalmente feminina e tratado como parte das obrigaçóes do 
casamento. Assim, verificamos no passado dessas mulheres, a presença, por vezes, de uma interdiçáo baseada num julgamento de valor segundo o qual mulher não precisa de estudo, vai à escola para "se perder, para procurar namorado" etc.

Esse tipo de interdição pode parecer, à primeira vista, coisa do passado. No entanto, prevalece ainda hoje e não apenas entre as mulheres mais velhas, oriundas de famílias numerosas que vivem do trabalho agrícola em cidades pequenas do interior. Na entrevista de Sonia Reis (2009, p. 175), por exemplo, vemos que o marido dá um ultimato à esposa, levando-a escolher entre a escola ou o casamento:

Só porque eu fui pra escola, meu marido se separou de mim. Eu falei pra ele: Quando eu era criança, meu pai não me deixou estudar, agora outro homem [marido] não vai impedir. Para meu marido e meu pai era mais importante que aprendesse a usar minhas mãos que minha cabeça. Porque eu não fiquei só usando as mãos, ou seja, lavando, passando, cozinhando, etc, o meu marido achou ruim e me largou com dois filhos [...]. (Madalena, 32 anos).

Cabe enfatizar que longe de se subordinar ao poder patriarcal manifesto na interdição, vemos nesta investigação que assim como outras tantas mulheres que não acataram os impedimentos, recusando o papel de submissa, essas mulheres fizeram valer o seu direto e construíram a possibilidade de voltar à escola.

Destacamos que a situação econômica familiar, a necessidade de contribuir com a manutenção da família ou mesmo de arcar sozinha com as despesas, faz com que as mulheres busquem o trabalho. Entretanto, a baixa escolaridade dificulta o ingresso no mercado de trabalho levando-as, por vezes, ao retorno à escola, em diferentes etapas da vida, neste caso, na modalidade EJA. Aliás, como nos lembra Resende (2008), a ocupação de empregada doméstica em meios letrados aproxima essas mulheres, de alguma maneira, do mundo da escrita. Afinal, o trabalho doméstico em residências de classe média requer a inserção em práticas de escrita que não são comuns nos seus meios. Portanto, estão imersas em um ambiente letrado e são solicitadas a desempenhar tarefas origem (fazer listas de compras, anotarem recado, etc.) que demandam algum domínio da competência de escrita.

Ao retornar aos estudos, não é incomum que a ocupação de empregada doméstica e suas responsabilidades conflitem com os horários de saída para a 
escola ${ }^{7}$. Ao retornar aos estudos, após os filhos criados, a patroa de Gilda teria comentado: "você não aprendeu nada até agora, minha filha, esquece! Palhaçada! Cê vai estudar pra que?”. Contudo, em seu relato enfatizou que desenvolvia atividades de toda ordem: cuidava da residência patronal, em bairro nobre da regiāo metropolitana, que estaria inteiramente sob sua responsabilidade; sua atuação iria desde orientação de outros empregados e prestadores de serviço, seguido do dos animais, jardins, manutenção da casa, alimentação da família até serviços de manicure, cabeleireira e depiladora da família. Relata por exemplo: "eu sai, e deixei o pessoal que foi colocar o aquecedor na piscina, o patrão amanhã vai falar na minha cabeça até, porque ele me cobra muito isso. Estar lá, pra eles fazerem o serviço, entendeu? Pra eu ver, pra perguntar, porque eu sou muito falante, eu pergunto de tudo [...]". Com esse depoimento ela reforça não apenas seu valor profissional, mas também sua capacidade de aprendizagem ${ }^{8}$.

Desse modo, o trabalho feminino tem sido uma imposição decorrente das necessidades que se interpóem às precárias condiçôes econômicas de vida de suas famílias. Fonseca (2004) destaca que o ingresso da mulher no mercado de trabalho não é exclusividade da vida moderna, mas uma realidade que sempre esteve presente para as mulheres pobres. Aquelas abandonadas pelos parceiros não tinham outra opção senão trabalhar, ou mesmo diante dos minguado salário do marido, recorrem ao trabalho para sustentar a família. Assim, "tentava-se escapar da miséria por seu próprio trabalho" (FONSECA, 2004, p. 516). Para elas, ocupaçóes como lavadeira, cozinheira, arrumadeira sempre foram as possíveis.

\section{Efeitos na escolarização?}

Todavia, se de um lado encontramos esse cenário de difícil conciliação de múltiplas responsabilidades, por outro percebemos que a escola está longe de compreender esses sujeitos nas suas diversidades e diferenças, ainda que as questóes de gênero atravessem essa instituição de ponta a ponta. As mães sobrecarregadas conseguem acompanhar a escolarizaçáo dos filhos? Se não tem acesso à escola não têm as competências necessárias para tanto, se têm acesso à escola, não lhes sobra tempo algum para fazê-lo. Podemos citar, neste caso, Antonia, 46 anos, ao se referir a alfabetização da filha: " [...] foi dificil, eu pagava as pessoas pra ficar com ela, quando descobri minha filha não sabia nada, nem um b com a, eu fui sentar com ela, pra ensinar, eu ensinei todos os fatos [matemática] pra ela [...]". 
Assim, veem-se forçadas a solicitar auxílio de terceiros, sejam eles amigos, parentes ou outros para sanar alguma dúvida relativa às tarefas escolares das crianças. Entretanto, algumas alunas dos primeiros anos do ensino fundamental, relatam que, na maior parte dos casos, as crianças dáo conta de suas tarefas (bem ou mal, com dedicação ou não) sozinhas, ou na própria escola, com auxílio de professores. Incluem-se casos em que houve problemas ou dificuldades na aquisição da escrita e da leitura na fase de alfabetização. Constatou-se, também, relatos de que o auxílio vem de tias, irmãs mais velhas, amigas da mãe ou do pai, quando presente. O caso de Gilda mostra-se singular, pois o companheiro, por seu regime de trabalho mais flexível (atua como porteiro), foi o responsável por acompanhar as crianças até a escola, frequentar reunióes de pais e ajudar nas tarefas escolares.

Do ponto de vista da transmissão entre geraçóes de valores e praticas ligadas à escola e à vida escolar, consoante com a própria condição de não leitoras, houve relatos sobre a precariedade do material de leitura em suas residências, especialmente literatura infantil, presente apenas quando doado por patróes e ou encaminhado pela escola. Raramente acompanharam se a criança lia ou lia bem (e com que qualidade) as tarefas escolares. Entre os impressos mencionados em suas narrativas apresentam-se os jornais populares, as revistas em quadrinhos e a Bíblia, além dos livros didáticos distribuídos pela escola. Como atividade de lazer e descanso familiar, parece predominar a presença da televisão, visitas à parentes e ida em eventos de natureza religiosa.

A exceção parece ser Gilda, que se distinguiria das demais mulheres pesquisadas. Seus filhos receberam dela o entusiasmo pela escola e pela leitura. Filhos de mãe leitora conviveram com diferentes textos, fruto de assinaturas de um dos jornais mais conhecidos de Belo Horizonte, O Tempo, além das revistas Época e Veja. Assim, uma filha formou-se em História e trabalha no Palácio das Artes, importante centro difusor de cultura de Belo Horizonte. Ainda assim, segundo ela, a filha não lhe leva mais ingressos de eventos, pois ela não comparecia. O lazer dela se resumiria em caminhar, mesmo a leitura, após seu retorno à escola teve seu tempo reduzido, já que ela cuida das tarefas domésticas também em sua residência, que incluía a execução de um cardápio diferenciado para a filha vegetariana. Mesmo sobre a neta ela afirmou: "[...] menina, Leda tem uma caixa de livros porque a gente dá livro pra ela desde pequeninha pra estimular, porque o pai e a mãe não [não incentivam e não são leitores]". A neta frequentava no período uma Unidade de Educação Infantil 
reconhecida em Belo Horizonte por situar em instituição de ensino superior. A avó pagava o transporte escolar.

Aprofundando um pouco mais nesse ponto, consideremos ainda os aportes de Marie Durut-Bellat (2005) acerca das desigualdades escolares. As conclusôes da pesquisadora reforçam aspectos que se mostram um tanto evidenciados no estudo que realizamos. A autora discute efeitos do contexto social de origem dos educandos e do contexto escolar no sucesso escolar e escolhas de carreira. Reforça ainda que, desde muito cedo, afloram correlaçóes entre desenvolvimento e a qualidade do ambiente da criança, e que as aprendizagens se encadeiam cumulativamente: "a vantagem das crianças de ambiente privilegiado é particularmente clara nas competências que serão mobilizadas na aprendizagem da leitura (reconhecimento das letras, por exemplo), ou no domínio de conceitos ligados ao tempo, sem dúvida porque essas capacidades foram objeto de aprendizagem familiar" (DURUTBELLAT, 2005, p. 16).

Dessa forma, assumindo a lógica de acumulação que perdura ao longo de todo percurso escolar, podemos afirmar que decorre dessa premissa também as desvantagens na escola que podem vir a se acumular. Vemos que os filhos de mães pouco escolarizadas acabam por receber um precário acompanhamento por parte delas. $\mathrm{O}$ material de leitura e a qualidade de leitura não recebem maior atenção, assim como atividades extracurriculares. Entretanto, não são mães omissas ${ }^{9}$, essa situação decorre de tantos outros fatores que já mencionamos e que atuam para compor um quadro em que elas detêm pouco capital escolar e pouco tempo para monitorar as atividades dos filhos, já que se encontram elas mesmas também na escola ${ }^{10}$.

Para a socióloga Durut-Bellat (2005), de um lado as maiores desvantagens escolares se encontram entre os meninos, filhos de famílias numerosas e monoparental ${ }^{11}$, as maiores vantagens são verificadas entre meninas de famílias nucleares de no máximo dois filhos. Somem-se a estas variáveis as escolhas de estabelecimento de ensino, as escalas individuais de atividades curriculares ou extracurriculares a que são submetidos, conforme as possibilidades e demandas familiares.

A autora reforça que o acúmulo da excelência escolar pode ser verificado desde o início da escolaridade. Das escolhas possíveis, o desencorajamento ou a perseverança são marcas de uma convicção socialmente construída sobre sua própria capacidade intelectual. A meritocracia náo deixa de ser uma marca da desigualdade social, 
[...] basta que a cada ano pequenas desigualdades sociais de êxito venham a agravar as diferenças de desempenho escolar, desempenho cuja inércia a seguir é grande. Basta também que, por ocasião de cada escolha as estratégias venham acentuar ainda mais as diferenças decorrentes das desigualdades de desempenho escolar. (DURUTBELLAT, 2005, p. 22).

Por fim, a autora questiona a responsabilidade da escola sobre a reproduçấo da desigualdade que leva os mais privilegiados socialmente a se beneficiarem de contextos escolares mais eficazes. Ela reforça que as famílias lutam com armas desiguais para se apropriarem dos melhores recursos escolares e proporcionar aos seus filhos melhor situação em relação àqueles que serão seus concorrentes no acesso às melhores carreiras e in fine as melhores posiçóes sociais. E como resultado a diminuição da desigualdade das oportunidades escolares fica mais nítida ao longo dos anos do que a diminuiçáo da desigualdade das oportunidades sociais.

Posto isso, ressaltamos que embora a literatura no campo das ciências sociais, antropologia, psicologia social, entre outras áreas, dediquem-se há muito tempo ${ }^{12}$ ao debate acerca das diferentes desigualdades enfrentadas pela mulher na sociedade brasileira, ainda hoje o campo da educação precisa dialogar com essa literatura. E esse diálogo, incipiente quando se trata de entender as dificuldades das mães trabalhadoras, encontra-se em estágio apenas embrionário quando tratamos de pensar os desafios que impóem essa realidade à escolarizaçáo da mulher na EJA.

\section{Notas}

${ }^{1} \mathrm{O}$ desenvolvimento da pesquisa contou ainda com a inestimável colaboração na equipe da Bolsista de Iniciação Científica Marilza Maximo e da doutoranda Ludimila Correa Bastos.

${ }^{2}$ Não cabe aqui apresentar detalhes sobre as instituiçóes, pois foram importantes apenas para localizar os sujeitos da pesquisa e nelas realizar as entrevistas, em horários predeterminados.

${ }^{3} \mathrm{O}$ relato de vida da depoente acima, inclui passagens dolorosas como estupro constante por parte do primeiro marido, pai do filho mais 
velho, entre outras agressóes que a levaram a denunciá-lo na delegacia de mulheres, onde ele teria cumprido três meses de pena. Após esse período, ela teria se refugiado no Convento das Carmelitas Descalças em São Paulo, com o menino.

${ }^{4}$ De mesmo modo, não entendemos por raça um dado biológico, mas um modo de construção da identidade social e política, assim como da subjetividade dos sujeitos, conforme Kabengele (1999).

${ }^{5}$ A autora reporta-se à análise da sociedade francesa neste caso, mas compreendemos poder transpor sua citaçáo para o caso deste estudo em questáo.

${ }^{6} \mathrm{O}$ perfil aqui apresentado concorda e corrobora com outros estudos que apresentam o perfil das mulheres na EJA, sendo Bastos (2011), Reis (2009), Valle (2010), entre outros.

${ }^{7}$ Segundo Gilda, desde pequena a escola teve enorme valor e foi muito incentivada pelo pai a estudar. Homem até então analfabeto, seu pai entra para a escola, na modalidade Mobral, mirando-se no exemplo da filha que havia aprendido a ler e ensinava-lhe as primeiras letras, e até hoje escreve textos e poemas de própria autoria. De acordo com ela, sempre registra em cadernos pessoais seus sonhos e reflexóes. Para além da influência e reconhecimento paterno, seus patróes e filhos deles também sempre a presentearam com livros, por reconhecerem nela uma leitora profícua.

${ }^{8}$ A saída a que se referiu teve em vista uma visita hospitalar ao filho que havia sido submetido a uma cirurgia por razão de um acidente.

${ }^{9}$ Sobre o mito da omissão parental em camadas populares ver Lahire. (2004).

${ }^{10}$ Há relatos de mães que acordam o filho às 5 horas da manhã, quando estão saindo para o trabalho para conversar sobre as tarefas escolares não realizadas ou mal feitas.

${ }^{11}$ Dizer monoparental significa, em boa parte dos casos, que a mãe responde por aspectos relativos à situação financeira, disciplina, saúde etc., sem a presença de um companheiro (seja ele o pai ou náo dos filhos) para dividir a responsabilidade, como é o caso de algumas das entrevistadas.

${ }^{12}$ Os estudos de Heleieth Iara Bongiovani Saffioti datam da década de 1960. Sua tese de livre docência para a Faculdade de Filosofia, Ciências 
e Letras de Araraquara da Universidade Estadual Paulista (UNESP), intitulada $\mathrm{A}$ mulher na sociedade de classe: mito e realidade, sob orientação do professor Florestan Fernandes, defendida em 1967 e publicada pela Vozes.

\section{REFERÊNCIAS}

ÁVILA. Maria Betânia. Divisão sexual do trabalho e emprego doméstico no Brasil. In: COSTA, Albertina et al. (Org.). Divisão sexual do trabalho, estado e crise do capitalismo. Recife: SOS CORPO; Instituto Feminista para a Democracia, 2010. p. 115-170.

ÁVILA. Maria Betânia. Presentación Mesa de discusión sobre trabajo domestico. Bogotá, n. 45, p. 229-232, 2013. Disponível em: <http://res.uniandes.edu. co/view.php/836/view.php>. Acesso em: 3 jul. 2013.

BASTOS, Ludimila Correa. Traçando metas, vencendo desafios: experiências escolares de mulheres egressas da EJA. 2011. 110p. Dissertação (Mestrado em Educação) - Universidade Federal Minas Gerais, Belo Horizonte, 2011.

DURUT-BELLAT, Marie. Amplitude e aspectos peculiares das desigualdades sociais na escola francesa. EDUCAÇÃO E PESQUISA, São Paulo, v. 31, n. 1, p. 13-30, jan./abr.2005

FONSECA, Cláudia. Ser mãe, mulher e pobre. In: DEL PRIORE, Mary. Historia das mulheres no Brasil. São Paulo: Contexto, 2004.

KABENGELE, Munanga, Rediscutindo a mestiçagem no Brasil: identidade nacional versus identidade negra: Petrópolis, RJ: Vozes, 1999.

LAHIRE, Bernard. Sucesso escolar nos meios populares. São Paulo: Editora Ática, 2004

MELO, Hildete Pereira de; CONSIDERA, Claudio Monteiro; DI

SABBATO, Alberto. Os afazeres domésticos contam. Economia e Sociedade, Campinas, SP, v. 16, n. 3 (31), p. 435-454, dez. 2007.

MINAYO, Maria Cecília de Souza (Org.). Pesquisa social: teoria, método e criatividade. Petrópolis, RJ: Vozes, 1994. 
REIS, Sonia Maria Oliveira Alves. A inserção dos egressos da educação popular na escola pública: tensão entre regulação e emancipação. 110p. 2009.

Dissertação (Mestrado em Educação) - Universidade federal de Minas Gerais, Belo Horizonte, 2009.

RESENDE, Patrícia Cappuccio de. Modos de participação de empregadas domésticas nas culturas do escrito. 2008. Dissertação (Mestrado em Educação) - Universidade Federal de Minas Gerais, Belo Horizonte, 2008.

ROSEMBERG, Fúlvia; PINTO, Regina P.; NEGRÃO, Esmeralda V. A educação da mulher no Brasil. São Paulo: Global, 1982.

SORJ. Bila. Os cuidados com a familia e as desigualdades de gênero e de classe. In: COSTA, Albertina et al. (Org.). Divisão sexual do trabalho, estado e crise do capitalismo. Recife: SOS CORPO; Instituto Feminista para a Democracia, 2010. p33-56.

VALLE, Mariana Cavaca Alves. A leitura literária de mulheres na EJA. 106p. 2010. Dissertação (Mestrado em Educação) - Universidade Federal de Minas Gerais, Belo Horizonte, 2010. 


\section{Aspectos de la escolarización de mujeres en la Educación de Jóvenes y Adultos}

\section{Resumen}

El presente estudio presenta una investigación de carácter cualitativo que utiliza como procedimientos metodológicos entrevistas con 14 mujeres madres de niños pequeños y que están matriculadas en la Educación de Jóvenes y Adultos nivel de primario, en instituciones educativas tradicionales y reconocidas (una pública y otra privada) de Belo Horizonte. El artículo discutirá aspectos relacionados con la escolarización y sus efectos dentro de la familia a la luz de contribuciones teóricas del campo de los estudios de género. Considerando a división por género de las tareas domésticas en la sociedad brasileña, es necesario debatir la sobrecarga de actividades impuesta a la mujer, madre, trabajadora. Con este fin, se examina la condición de su escolaridad, así como la relación con la de sus hijos y con la cultura escrita familiar. Se observa como resultado el esfuerzo de negociación en la búsqueda de garantizar su posibilidad de matricularse en la escuela y las dificultades que enfrentan para ayudar la educación de sus hijos en la triple condición de madre, trabajadora y estudiante.

Palabras claves: Género. Educación de adultos. Cultura escrita.

\section{Aspects of women's schooling in EJA \\ Abstract}

Starting from a qualitative research conducted through interviews with 14 women who are mothers of small children and who also are enrolled in the Education for Youngsters and Adults primary school in two renowned and traditional education institutions (public and private) in Belo Horizonte, this work discusses aspects relating to schooling and its effects in the family household. Considering the division by gender of the housework tasks in the Brazilian Society, this work debates the overload imposed upon the working mother, examines her schooling condition, her relation to her children's schooling and the family's writing culture. It's evident as a result, the negotiation effort they undertake to ensure their ability to enroll in school and the difficulties they face to monitor the education of the children in his triple condition of mother, worker and student.

Keywords: Gender. Adult's Education. Writing culture. 


\section{Carmem Lucia Eiterer}

E-mail: carmenl@ufmg.br

Jacqueline D'arc Dias

E-mail: jacquelinematufmg@gmail.com

\section{Marina Coura}

E-mail:coura.marina@gmail.com

Recebido em: 18/12/2013

Versão final recebida em: 10/2/2014

Aprovado em: 11/2/2014 